\title{
Snail Driving Alternative Splicing of CD44 by ESRP1 Enhances Invasion and Migration in Epithelial Ovarian Cancer
}

\author{
Le Chen ${ }^{\mathrm{a}}$ Ying Yao ${ }^{\mathrm{b}}$ Lijuan Sun ${ }^{\mathrm{a}}$ Jiajia Zhou ${ }^{\mathrm{a}}$ Minmin Miao ${ }^{\mathrm{a}}$ Shujuan Luo \\ Guanming Denga Junjun Lic Jing Wang ${ }^{\text {a }}$ Jie Tang ${ }^{\mathrm{a}}$ \\ aDepartment of Gynecologic Oncology, Hunan Cancer Hospital, the Affiliated Cancer Hospital of \\ Xiangya School of Medicine, Central South University, Changsha, ${ }^{b}$ Department of gynecology and \\ obstetrics, the First People's Hospital of Yueyang, Yueyang, 'Department of Pathology, Hunan Cancer \\ Hospital, the Affiliated Cancer Hospital of Xiangya School of Medicine, Central South University, \\ Changsha, P.R. China
}

\section{Key Words}

Epithelial ovarian cancer • ESRP1 • EMT • CD44 • Invasion and migration

\begin{abstract}
Background/Aims: Our study aims to investigate the role, effect and mechanisms of ESRP1 (epithelial splicing regulatory protein 1) in epithelial-mesenchymal transition (EMT) in epithelial ovarian cancer (EOC). Methods: Microarray and immunohistochemical analysis of ESRP1 expression were performed in EOC cases. The correlations between ESRP1 expression and clinical factors on EOC were assessed. Lentivirus-mediated RNA interference and EGFP vector which contains ESRP1 gene were used to down-regulate and up-regulate ESRP1 expression in human EOC cell lines. Roles of ESRP1 in cell growth, migration and invasion of EOC cells were also measured by Cell Counting Kit- 8 and Transwell systems in vitro and by a nude mice intraperitoneal transplantation model in vivo. Results: By the analysis of Gene Expression Omnibus (GEO) $(p<0.05)$ and our own microarray data $(p<0.001)$, ESRP1 expression in EOC was significantly different from normal ovarian tissue. It was abundant in the nuclei of cancer cells and in malignant lesions. However, it was weakly expressed or negative in both normal and benign lesions. High ESRP1 expression in EOC was associated with poor clinical outcomes. Decreased ESRP1 expression significantly increased cell migration and invasion both in vivo and in vitro. Snail strongly repressed ESRP1 transcription through binding to the ESRP1 promoter in EOC cells. Furthermore, ESRP1 regulated the expression of CD44s. Down-regulated ESRP1 resulted in an isoform switching from CD44v to CD44s, which modulated epithelial-mesenchymal transition (EMT) program in EOC. Up-regulatin of ESRP1 was detected in mesenchymal to epithelial transition (MET) in vivo. Conclusions: ESRP1 regulates CD44 alternative splicing during the EMT process which plays an important role in EOC carcinogenesis. In addition, ESRP1 is associated with disease prognosis in EOC.

L. Chen and Y. Yao contributed to this paper equally.




\section{Cellular Physiology Cell Physiol Biochem 2017;43:2489-2504 \\ and Biochemistry Published $\begin{aligned} & \text { DOI: 10.1159/000484458 } \\ & \text { (c) 2017 The Author(s). Published by S. Karger AG, Basel } \\ & \text { www.karger.com/cpb }\end{aligned}$ \\ Chen et al.: ESRP1 Plays an Important Role in EOC through EMT Process}

\section{Introduction}

Ovarian cancer is the third most common gynecological cancer in the world but the leading cause of death from gynecological malignancies. $90 \%$ of ovarian cancer is epithelial ovarian cancer (EOC) [1]. Debulking surgery and chemotherapy are standard treatment for EOC, by which the 5-year survival rate of EOC is still unsatisfactory due to extensive local tumor invasion and early metastasis [1-5]. Thus, understanding the mechanisms that regulate EOC invasion/ metastasis is crucial to the development of new and more effective therapies. Epithelial-mesenchymal transition (EMT) is a tightly regulated process, which is critical for embryogenesis. It is abnormally activated during cancer metastasis and recurrence. Such changes result in loss of cell polarity and cell-cell adhesions, cytoskeletal reorganization, downregulation of epithelial E-cadherin, upregulation of mesenchymal $\mathrm{N}$-cadherin, and enhanced resistance to cell death. These newly acquired properties lead to increased invasiveness and cell migration [6].

The development of metastasis requires EMT to enable cancer cells to migrate from their primary tumor sites. A mesenchymal to epithelial transition (MET) is proposed to be a necessary driving force for re-colonization at distant sites, which allows for tumor engraftment and growth of cancer cells at metastatic sites. Several studies clearly support the role of an EMT in dissemination and the necessity of a subsequent MET for colonization and macro-metastasis [7-9]. The phrase "adaptive plasticity" explains how cancer cells gain selective growth and survival capabilities through phenotypic changes in response to their environment. However, those mechanisms that initiate and enable phenotypic changes are not fully defined. Understanding the mechanisms that regulate the EMT or MET process would provide us with key insight.

The potential role of alternative splicing, which represents an important gene regulatory mechanism in EMT or MET, may lead to aggressive cellular behavior that contributes to cancer progression. Alternative RNA splicing is a process by which cells generate multiple protein products from a single gene. Nearly all mammalian genes undergo alternative splicing [10, 11]. Aberrant alternative splicing frequently occurs in cancer $[12,13]$, but no direct splicing pathways have yet been established in EOC. In this study, we specifically addressed this issue by studying the role of ESRP1 in EOC. Epithelial-specific RNA binding protein does regulate alternative splicing events in the EMT process [14]. It was reported that some transcription factors such as $\delta \mathrm{EF} 1$ family proteins, $\delta \mathrm{EF} 1$ and SIP1, were increased after TGF- $\beta$ treatment, and subsequently repressed the expression of ESRP1 [15]. Conversely, in these TGF- $\beta$-treated cells, ectopic ESRP1 inhibited the conversion of alternative splicing pattern of epithelial types into those of mesenchymal types, as well as down-regulation of the expression of E-cadherin [15]. Some studies also indicated that ESRP1 was associated with degree of differentiation and overall survival rate in multiple tumors [16-18]. Some experts have demonstrated that ESRP1 regulated alternative splicing of FGFR2, CD44, p120-catenin (CTNND1) and Mena (ENAH) during the EMT process $[14,19]$. For example, ESRP1 enhanced splicing of exon IIIb and silenced the exon IIIc in FGFR2 $[14,19]$. In addition, FGFR2 and CD44 isoforms were associated with cell proliferation and invasion in pancreatic cancer $[20,21]$.

However, the functional relevance and molecular mechanisms of the alternative splicing by ESRP1 remain unclear in EOC. Our study aims to reveal the important role of the ESRP1 in tumor progression, invasion and metastasis, and to provide some potential clinical application in EOC.

\section{Materials and Methods}

\section{Patients and samples}

All study participants signed an informed consent form which was reviewed by the Institutional Review Board of Hunan Cancer Hospital (Changsha, China). All tissue samples were verified by histopathology. Multiple tissue specimens- including 51 cases of normal ovarian tissues, 38 cases of benign ovarian tumors 


\section{Cellular Physiology Cell Physiol Biochem 2017;43:2489-2504 \begin{tabular}{ll|l} 
DOI: 10.1159/000484458 & $\begin{array}{l}\text { O 2017 The Author(s). Published by S. Karger AG, Basel } \\
\text { www.karger.com/cpb }\end{array}$ \\
\hline
\end{tabular}}

Chen et al.: ESRP1 Plays an Important Role in EOC through EMT Process

and 109 cases of primary EOC tissues - were used for tissue microarray and immuno-histochemistry. EOC patients were identified from a database containing clinical pathology and follow-up data. All EOC patients were treated with standard protocols in accordance with NCCN (The National Comprehensive Cancer Network) clinical practice guideline for EOC [22] by gynecological oncologists in the Hunan Cancer Hospital between 2008 and 2012. Surgical evaluation was used to determine the clinical stages and presence of metastases according to the 2014 FIGO classification [23], whereas histopathologic analysis was performed by gynecologic pathologists to assess cancer types and grades. Among the 109 cases of primary EOC samples, 70 were serous carcinoma, 24 were mucinous carcinoma, 10 were endometroid carcinoma, and 5 were clear cell carcinoma. Follow-up of all patients was performed for up to 3 years.

\section{Antibodies}

Antibodies used for IHC and Western Blot included ESRP1 (Abcam plc, Cambridge, MA, USA), ESRP2 (Abcam plc, Cambridge, MA, USA), CD44s (R\&D Systems, Minneapolis, MN, USA), $\alpha$-SMA (Bioworld, Nanjing, Jiangsu, China), Snail (Millipore, Billerica, MA, USA) and $\beta$-actin (Abcam plc, Cambridge, MA, USA). Horseradish peroxidase-conjugated secondary antibodies, goat anti-rabbit, and rabbit anti-mouse were purchased from Boster (Wuhan, Hubei, China).

Tissue microarray (TMA) and Immuno-histochemistry (IHC)

As was previously described [24], the following procedures were used for TMA and IHC. Briefly, tissue was fixed in $4 \%$ paraformldehyde for at least 24 hours. $4 \mu \mathrm{m}$ sections were prepared on the microtome and placed on clean, positively charged microscope slides. TMA sections were incubated overnight with ESRP1 (1:50) primary antibody. Antigen-antibody reactions were visualized with 3, 3-diaminobenzidine, the chromogenic substrate for peroxidase, and hematoxylin was used to counterstain the tissue.

ESRP1 expression in each case was rated according to a score that added a scale of intensity of staining to the area of staining as described [17] . More than 10 high-power fields were chosen randomly, and $>1$, 000 cells were counted for each section. The intensity of staining was graded on the following scale: 0 , no staining; $1+$, mild staining; $2+$, moderate staining; $3+$, intense staining. The area of staining was assessed as follows: 0 , no staining of cells in any microscopic fields; $1+,<30 \%$ of tissue stained positive; $2+$, between $30 \%$ and $60 \%$ stained positive; $3+,>60 \%$ stained positive. The score when summed (extension + intensity) was therefore, between 0 to 6 . A combined staining score (extension + intensity) of $\leq 2$ was considered to be a negative staining (low staining); a score between 3 and 4 was a moderate staining; whereas a score between 5 and 6 was a strong staining.

\section{RNA extraction, Gene microarray and Quantitative real-time PCR ( $q R T-P C R$ )}

Total RNA from cells or fresh tissues was extracted using the Trizol Kit (Life Technologies, Rockville, MD, USA). Gene microarray analysis of gene expression profiles in ovarian tumors from three EOC patients (FIGO stage IIIC, high grade serous ovarian cancer) and three normal ovarian tissues was performed using Affymetrix HTA 2.0 Array (Affymetrix Inc, Santa Clara, California, USA). For these three EOC patients, primary surgical evaluation was used to determine the clinical stages and presence of metastases according to the 2014 FIGO classification [23], whereas histopathologic analysis was performed by gynecologic pathologists to assess cancer types and grades. QRT-PCR was performed using Accurate Genomic DNA Removal kit (Applied Biological Materials Inc, BC, Canada) and SYBR ${ }^{\circledR}$ Green Realtime PCR Master Mix kit (Takara Bio, Tokyo, Japan). The $\beta$-actin gene was used as a control for this reaction. The data was analyzed using the $\Delta \Delta \mathrm{Ct}$ method and normalized to $\beta$-actin levels. The primer sequences used in RT-PCR are presented in Table 1. All qRT-PCR experiments were repeated at least three times.

\section{Cell culture}

The human EOC cell lines H08910, A2780, SKOV3 and OVCAR5 were purchased from the Type Culture Collection of the Chinese Academy of Sciences (Shanghai, China). All cell lines were cultured in Dulbecco's modified Eagle's medium (DMEM, Gibco, USA) supplemented with 10\% fetal bovine serum (Gibco, USA) as we described previously [24]. Cells were incubated with recombinant human TGF- $\beta(10 \mathrm{ng} / \mathrm{mL})$ purchased from R\&D Systems (Minneapolis, MN, USA) for 24 to 48 hours for the TGF- $\beta$-induced EMT. RNA and protein samples were then extracted. 
Cell Physiol Biochem 2017;43:2489-2504

\begin{tabular}{l|l}
\hline DOI: 10.1159/000484458 & (C) 2017 The Author(s). Published by S. Karger AG, Basel
\end{tabular}

Published online: October 31, 2017 www.karger.com/cpb

Chen et al.: ESRP1 Plays an Important Role in EOC through EMT Process

RNA Interference

Small double-stranded siRNA oligonucleotides chemically synthesized by SangonBiotech (Shanghai, China) were tranfected into EOC cells using Lipofectamine 3000 transfection kit with $10 \mathrm{nM} / \mathrm{mL}$ to induce shortterm silencing of genes of CD44. The siRNA sequences used in this study was: human CD44 5'-GAACGAAUCCU - GAAGACAUdTdT -3'. The effect of CD44 silencing was detected by qRT-PCR.

Human ESRP1 ShRNA was designed by Shanghai Genechem Co.LTD. This synthetic oligonucleotide used was: 5'-GATCCGCTCTGGTTAGGTTT - GTAAGT GATT CAAGAGAT CACTTA - CAAACCTAACCAGAGCTTTTTTA -3 '. It has been proven to be efficient in ESRP1 silencing experiments. To knock out ESRP1 in the OVCAR-5 and H08910 cancer cell lines, cells were seeded in a 6-well tissue culture plate with $2 \times 10^{5}$ / well one day prior to infection. The complete culture solution was replaced by the infectionenhanced solution with $5 \mu \mathrm{g} / \mathrm{ml}$ polybrene (AMRESCO, Houston, Texas, USA), and the packed lentivirus was added to cells with multiplicity of infection (MOI=70). After 16 hours, the lentivirus solution was replaced with complete culture solution. Infected cells were sub-cultured every 5-7 days and the stable transfected cells were selected by puromycin $(1 \mu \mathrm{g} / \mathrm{mL})$. The effect of ESRP1 silencing was detected by qRT-PCR and Western Blot.

\section{Dual-Luciferase Reporter assay system}

Dual-Luciferase Reporter assay system was constructed as reported [25]. The ESRP1 promoter region including four E-boxes (CANNTG) structures was PCR-amplified from genomic DNA which was isolated from H08910 cells. Sequences of primers used in PCR were: forward: AGTCGAGCTCTGGTTTGAAGGAGCCAATG; reverse: GACTAG ATCTCTTCCTTGCTACTGCTAGTGC. PCR product was sequenced by SangonBiotech (Shanghai, China) and validated by GenBank database (NCBI Reference Sequence: NT_008046.17), which contained all four E-boxes structures. The ESRP1 promoter construct was created by cloning the above PCR product into the SacI and BglII sites of the pGL3-Basic vector. Briefly, H08910 cells were seeded in a 24-well plate in antibiotic-free media.Cells were co-transfected ESRP1 promoter construct with either pENTER-Snail or EV-pENTER (NC) plasmid after attachment. PRL-TK plasmid (Promega, WI, USA) was also transfected in each group and served as an internal control reporter. Cells were collected 48 hours after transfection and analyzed using the Dual-Luciferase Reporter Assay System (Promega, WI, USA). Luciferase activity was detected using an M200 microplate fluorescence reader (Tecan, Beijing, China) and the results were normalized against Renilla luciferase activity. Transfection experiments were duplicated and repeated in at least three independent experiments. 


\section{Cellular Physiology Cell Physiol Biochem 2017;43:2489-2504 \begin{tabular}{l|l|l} 
and Biochemistry Published online: October 31, 2017 & $\begin{array}{l}\text { C } 2017 \text { The Author(s). Published by S. Karger AG, Basel } \\
\text { www.karger.com/cpb }\end{array}$ \\
\hline
\end{tabular}}

Chen et al.: ESRP1 Plays an Important Role in EOC through EMT Process

\section{Immunofluorescence (IF)}

Cells were plated on sterilized cover slips in 6-well plates and cultured for 24 hours at $37^{\circ} \mathrm{C}$. Then, the cells were fixed in 4\%Paraformaldehyde for 10 minutes, followed by permeabilization for 10 minutes in $0.5 \%$ Triton X-100 in PBS. Before being incubated at $4{ }^{\circ} \mathrm{C}$ with primary anti- $\alpha$-SMA antibody diluted in PBS (1:100) overnight, cells were blocked with $3 \% \mathrm{H}_{2} \mathrm{O}_{2}$ for 15 minutes, then with $10 \%$ normal goat serum for 15 minutes at room temperature. A second antibody, Cy3-labeled mouse anti-goat IgG (purchased from Boster, Wuhan, China), was added at room temperature for another 2 hours afterwards. Finally, DAPI was added for 5 minuntes at room temperature. We used immunofluorescence to examine the cells under using the Olympus BX53 microscope (Olympus, Tokyo, Japan).

\section{CCK-8 assay}

Cell proliferation was determined by Cell Counting Kit-8 (CCK-8, Dojindo, Japan). EOC Cells were seeded by density of $2 \times 10^{3}$ cells /well, and incubated with prepackaged CCK-8 solution at $37^{\circ} \mathrm{C}$ for 3 hours, after that, cultured in DMEM medium with 10\% FBS for 24, 48, and 72 hours. We spectrophotometrically measured the absorbance at $450 \mathrm{~nm}$ of the supernatant, by using a plate reader (Bio-Rad Laboratory, Hercules, CA, USA). Cell counts were determined with a calibration curve. A minimum of three independent assays were performed.

\section{Transwell migration and invasion assay}

Transwell systems (Corning, USA) were used as we previously described [24] to evaluate metastasis ability of cancer cells. Briefly, for invasion assay, Matrigel (BD Biosciences) was added to the upper surface of a polycarbonic membrane (pore size $8 \mu \mathrm{m}$ ) to form a thin gel layer to serve as the ECM. The filter was dried overnight in a laminar hood, and then reconstituted with $100 \mu \mathrm{l}$ of PBS at $37 \stackrel{\circ}{\circ} \mathrm{C}$ for $2 \mathrm{~h}$. The upper compartment of the filter contained the treated cells at a density of $5 \times 10^{5}$ cells/well in $100 \mu$ l of DMEM. The bottom filter was filled with $600 \mu \mathrm{l}$ of conditional medium. After 24-hour incubation at $37 \stackrel{\circ}{\circ} \mathrm{C}$ with $5 \% \mathrm{CO}_{2}$, the polycarbonic membrane was fixed with $4 \%$ paraformldehyde for 10 minutes and stained with $0.2 \%$ crystal violet solution. Then, the cells on the upper surface of the filter were removed by wiping with a cotton swab. Cells that had penetrated to the lower surface of the filter were counted under an Olympus microscope in three randomized fields at a magnification of 100×. Cell migration assay was carried out in a transwell filter on membrane filters, which were not coated with Matrigel. A minimum of three independent assays were performed.

\section{Western Blot}

A summary of our Western Blot protocol [24] is as follows. The cell lysate used for Western Blot was extracted within RIPA lysis buffer (Cwbio, Beijing, China), which contains protease inhibitors (Roche, Germany). We quantified proteins by using the BCA Protein Assay Kit (Cwbio, Beijing, China). The Western blot system was established by using a BioRad Bis-Tris Gel system (Bio-Rad, CA, USA). Briefly, we separated approximately $40 \mu \mathrm{g}$ of protein on SDS-PAGE and transferred it to PVDF membranes (Millipore, Danvers, MA, USA). The membranes were blocked by $5 \%$ nonfat milk. Then, the membranes were incubated overnight with the primary antibody (1:100 for ESRP1, 1:500 for Snail, 1:500 for CD44s) at $4^{\circ} \mathrm{C}$, followed by a brief wash with PBST and subsequent incubation with a secondary antibody for 1 hour at $37^{\circ} \mathrm{C}$. An anti- $\beta$-actin antibody was used as a loading control. Finally, ECL solution (Millipore, Billerica, MA, USA) was added to cover the blot surface. The signals were captured and the intensity of the bands was quantified by using the Bio-Rad ChemiDoc XRS+ system (Bio-Rad, CA, USA). At least three independent experiments were performed.

\section{Nude mice, intraperitoneal transplantation and metastasis assay}

5 to 7 -week-old female balb/c nude mice for use in this experiment were purchased from the Shanghai Institutes for Biological Sciences of the Chinese Academy of Sciences (China). We intraperitoneally injected each mouse with $4 \times 10^{6}$ EV-H08910 or $4 \times 10^{6}$ sh-ESRP1-H08910 cells. Mice were fed a regular diet and monitored closely. After four weeks, tumors were excised from the mice. We measured each tumor's volume, quantity and weight. The experimental protocol was approved by the Institutional Animal Care and Use Committee of the Hunan Cancer Hospital. 
Statistical analysis

All quantitative data were presented as mean \pm SEM values. Data from two groups were compared using Student's T test. The chi-square test was used to analyze the correlation between ESRP1-expression and clinicopathological features. Cumulative survival rate was calculated with the Kaplan-Meier method, and the significance of differences in survival rates was analyzed by the log-rank test. Cox proportional hazard models were used to assess the prognostic significance of ESRP-1 expression and several clinicopathologic parameters. $p<0.05$ was considered statistically significant. Computations were performed using the SPSS 18.0 (IBM, Armonk, NY, USA).

\section{Results}

ESRP1 was up-regulated in epithelial ovarian cancer and associated with poor outcomes

Transcripts with greater than 1.5-fold differences measured by gene microarray test in either direction between the two groups (ANOVA $p$-value $<0.05$ ) were identified. The top ten genes in either direction $(\mathrm{p}<0.05)$ are shown (Fig. 1 Aa), and ESRP1 was significant up-regulated in EOC cases (Fold change $=128.94$, $p$-value $=0.003)$. Next, we validated ESRP1 expressions in three different datasets from the NCBI GEO (Gene Expression Omnibu) database, which totally including 68 EOC samples and 27 normal ovarian samples (Table 2) [26-28]. Within our microarray data, ESRP1 was consistently and sig-

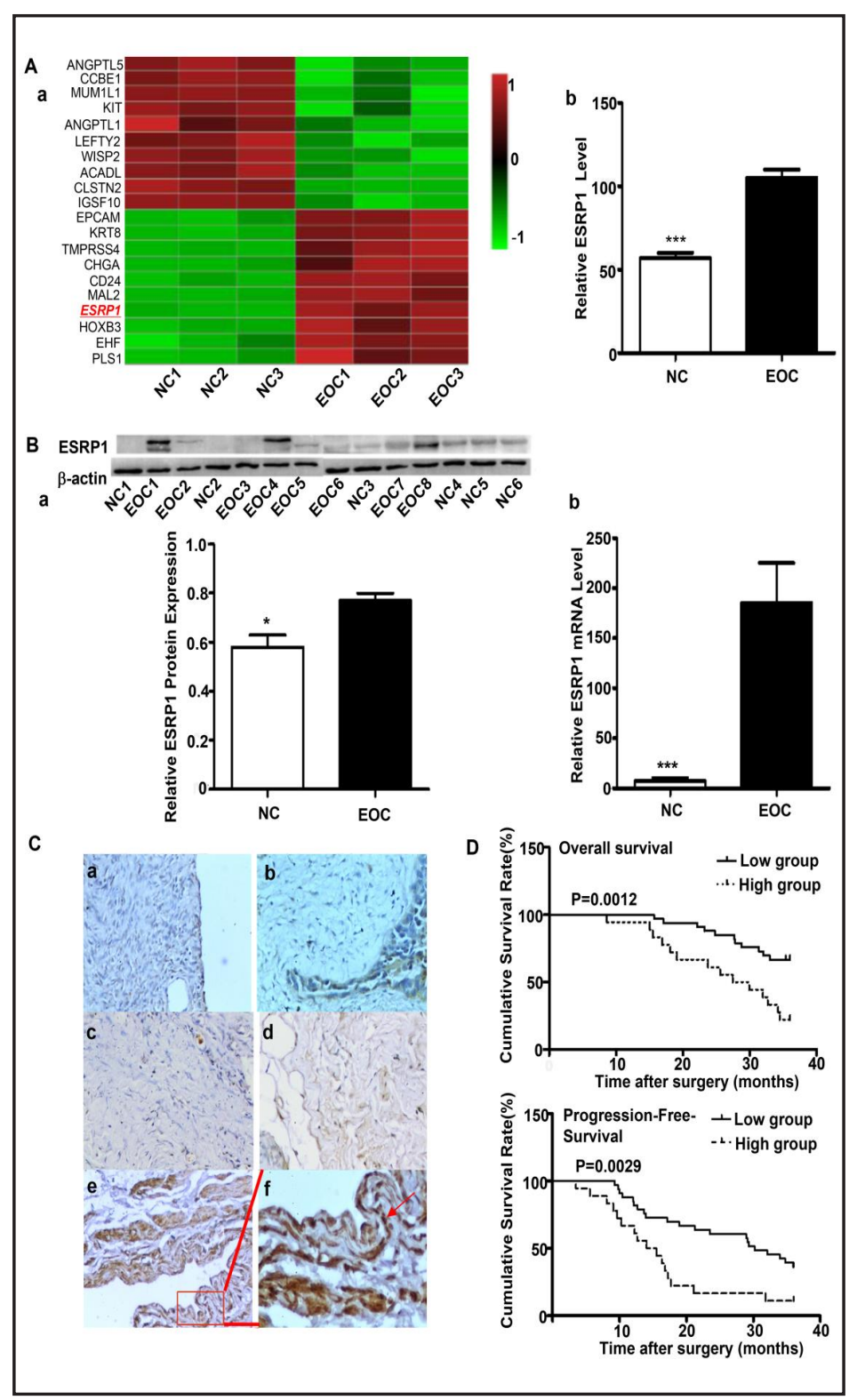

Fig. 1. ESRP1 was up-regulated in epithelia ovarian cancer and associated with poor outcomesA: Heat map of the top ten genes $(p<0.05)$ in both directions by an Affymetrix HTA 2.0 microarray test, in which ESRP1 was significant up-regulated in EOC tissues (a). This up-regulation was validated in GEO datasets $\left(b,{ }^{* * *} p<0.001\right)$. Error bars indicate SEM. B: ESRP1 levels in six normal ovarian and eight EOC tissues were measured by Western Blot $\left(\mathrm{a}-\mathrm{b},{ }^{*} \mathrm{p}<0.05\right)$ and $\mathrm{qRT}-\mathrm{PCR}\left(\mathrm{c},{ }^{* * *} \mathrm{p}<0.001\right)$. $\beta$-actin served as a loading control. Error bars indicate SEM. C: In immuno-histochemistry test, ESRP1 was expressed negative or weakly in normal ovarian tissues (a, x200; b, x200) and benign ovarian tumors (c, x200; d, x200), while ESRP1 was abundant in the nuclei of EOC cancer cells (e, x200; f, x400. Red box in e indicates the amplified field presented as $\mathrm{f}$, red arrow in $\mathrm{f}$ shows the positive staining). D: The over all survival rate (OS) and progression-free survival rate (PFS) of the high ESRP1 expressing group was significantly lower than that of the low ESRP1 expressing group (OS: $p=0.001$, PFS: $p=0.003$ ). 


\section{Cellular Physiology Cell Physiol Biochem 2017;43:2489-2504 \begin{tabular}{l|l|l} 
DOI: 10.1159/000484458 & $\begin{array}{l}\text { O 2017 The Author(s). Published by S. Karger AG, Basel } \\
\text { www.karger.com/cpb }\end{array}$
\end{tabular}

Table 2. Datasets selected from NCBI GEO (Gene Expression Omnibu) database

\begin{tabular}{lcccc}
\hline Contributor & GEO Accession & Microarray platform & \# of & \# of \\
& & & EOC & OSE \\
\hline Shubin Shahab & GSE23391 & Affymetrix Human Genome U133 Plus 2.0 Array & 3 & 5 \\
Nathan J. Bowen & GSE14407 & Affymetrix Human Genome U133 Plus 2.0 Array & 12 & 12 \\
Michael Birrer & GSE18520 & Affymetrix Human Genome U133 Plus 2.0 Array & 53 & 10 \\
Total & & & 68 & 27
\end{tabular}

nificantly expressed higher in these EOC cases (Fig. 1 Ab). This was confirmed by both Western Blot (Fig. 1 Ba-b) and qRTPCR (Fig. $1 \mathrm{Bc}$ ). We also assessed ESRP1 expression levels in a tissue microarray that included 51 of the normal ovarian tissues and benign ovarian tumors and 109 cases of EOC samples by IHC. We found that ESRP1 was expressed negatively or weakly in the normal ovarian tissues and benign ovarian tumors while ESRP1 was abundant in the nuclei of EOC cancer cells (Fig. $1 \mathrm{Ca}-$ f).

High expression of ESRP1 in EOC may indicate some clinical relevance. To examine the correlations between ESRP1 expression and clinical factors, we divided 109 EOC cases into two groups (Negative/Low group and Moderate/High group) based on ESRP1 expression determined by the immuno-histochemical score. The high ESRP1 expression group $(n=50)$ had higher proportions of advanced FIGO stage $(p=0.002)$, high tumor grade $(p=0.000)$ and residual tumour $\geq 1 \mathrm{~cm}$ cases $(p=0.000)$ than low ESRP1 expression group ( $\mathrm{n}=59)$ (Table 3$)$. Using univariate analysis (Cox's proportional hazards model), the following variables were found to be significantly associated with OS and PFS: FIGO stages, tumor grades, residual tumor volume and expression levels of ESRP1 ( $p<0.05$; Table 4 and Table 5). Survival curves caculated by Kaplan-Meier method and analyzed by log-rank test showed that the survival rates in the low ESRP1 expression group was significantly longer than that in high ESRP1 expression group (Fig. 1 D. Median OS: > 36.00Vs. 28.27 months, $p=0.001$; median PFS:33.24 Vs. 14.85 months, $p=0.003$ ). Multivariate analysis showed that FIGO stages, tumor grades, residual tumor volume and expression levels of ESRP1 had an independent prognostic effect on OS ( $p<0.05$; Table 4) and PFS ( $p<0.05$; Table 5). 
Table 4. Prognostic factors on OS were analyzed by univariate and multivariate Cox's propotional hazards models

\begin{tabular}{|c|c|c|c|c|}
\hline & \multicolumn{2}{|l|}{ Univariate analysis } & \multicolumn{2}{|c|}{ Multivariate analysis } \\
\hline & $\operatorname{HR}(95 \% \mathrm{CI})$ & p-value & $\mathrm{HR}(95 \% \mathrm{CI})$ & p-value \\
\hline Age (years) $(\geq 55$ Vs. $<55)$ & $1.04(1.00-1.08)$ & 0.157 & $1.04(1.00-1.08)$ & 0.157 \\
\hline Histology Types(Serous Vs. Non-serous) & $0.68(0.31-1.97)$ & 0.203 & $1.15(0.42-2.56)$ & 0.808 \\
\hline Grade (Low Vs. High) & $2.58(1.36-4.74)$ & 0.029 & $2.12(1.31-4.15)$ & 0.045 \\
\hline FIGO Stage(I-II Vs.III-IV) & $5.21(1.88-11.92)$ & $<0.001$ & $4.23(1.12-9.75)$ & $<0.001$ \\
\hline 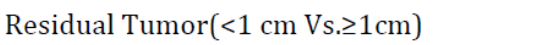 & $2.79(1.58-3.94)$ & 0.002 & $2.45(1.34-3.78)$ & 0.004 \\
\hline ESRP1(Negative/LowVs. Moderate /High ) & $4.32(1.75-10.42)$ & 0.0012 & $3.94(1.46-9.77)$ & 0.0023 \\
\hline
\end{tabular}

Table 5. Prognostic factors on PFS were analyzed by univariate and multivariate Cox's propotional hazards models. PFS: progression-free-survival

\begin{tabular}{llccc}
\hline & \multicolumn{1}{c}{ Univariate analysis } & \multicolumn{2}{c}{ Multivariate analysis } \\
& HR $(95 \% \mathrm{CI})$ & p-value & HR $(95 \% \mathrm{CI})$ & p-value \\
\hline Age (years) $(\geq 55$ Vs. $<55)$ & $0.97(0.72-1.69)$ & 0.360 & $0.70(0 . .64-1.58)$ & 0.402 \\
Histology Types(Serous Vs. Non-serous) & $0.85(0.61-1.77)$ & 0.216 & $1.04(0.72-1.97)$ & 0.607 \\
Grade (Low Vs. High) & $1.58(0.96-3.74)$ & 0.089 & $1.77(1.41-2.95)$ & 0.069 \\
FIGO Stage(I-II Vs.III-IV) & $4.21(2.37-9.71)$ & $<0.001$ & $3.53(2.02-8.55)$ & $<0.001$ \\
Residual Tumor(<1 cm Vs. $\geq 1 \mathrm{~cm})$ & $3.79(2.08-4.94)$ & 0.001 & $3.15(1.98-3.99)$ & 0.002 \\
ESRP1(Negative /Low Vs. Moderate /High ) & $3.22(1.55-7.54)$ & 0.003 & $2.95(1.36-6.67)$ & 0.004 \\
\hline
\end{tabular}

ESRP1 down-regulation promoted the invasion and migration by inducing EMT in human EOC cell lines

To assess the role of ESPR1 in EOC cells, we initially characterized ESRP1 expression in human EOC cell lines by qRT-PCR. The ESRP1 expression was high in H08910 and OVCAR-5 cells, but low in A2780 and SKOV-3 cells (data not shown). We down-regulated ESRP1 expression in H08910 and OVCAR- 5 cells by using sh-ESRP1 lentivirus vector. Stable transfected cells (sh-ESRP1-H08910 and sh-ESRP1- OVCAR-5) were confirmed by qRT-PCR and Western Blot. By comparing the stable transfected cells with mock-transfected cells (EV-H08910 and EV-OVCAR-5) (Fig. 2 A), we found that there was no significant change in cell proliferation between EV-H08910 and shESRP1-H08910, or EV-OVCAR-5 and shESRP1-OVCAR-5 (data not shown). However, the down-regulation of ESRP1 significantly increased migration $(p<0.001)$ and invasion $(p<0.001)$ of EOC cells (Fig. 2 B). Furthermore, we observed that the increasing the expression of ESRP1 in EOC cell line SKOV-3(Fig. 3 


\section{Cellular Physiology Cell Physiol Biochem 2017;43:2489-2504

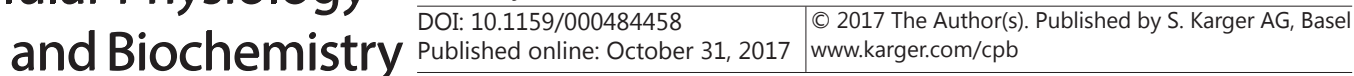 \\ Chen et al.: ESRP1 Plays an Important Role in EOC through EMT Process}

Fig. 2. ESRP1 downregulation promoted the invasion and migration by inducing EMT in human EOC cell linesA: Stable down-regulated ESRP1 expression in H08910 and OVCAR-5 cells was confirmed by qRT-PCR and Western Blots. $\beta$-actin served as a loading control. Error bars indicate SEM $\left({ }^{* * *} \mathrm{p}<0.001\right) . \quad$ B: Down-regulation of ESRP1 in H08910 and OVCAR-5 increased migration and invasion of EOC cells significantly confirmed by a Corning Transwell System. Error bars indicate SEM $\quad\left({ }^{* *} \mathrm{p}<0.001\right) . \quad \mathrm{C}$ : Up-regulated ESRP1 expression in SKOV-3 cells was confirmed by qRT$\operatorname{PCR}\left({ }^{* * *} \mathrm{p}<0.001\right)$ and Western Blot. $\beta$-actin served as a loading control. Error bars indicate SEM. D: Up-regulation of ESRP1 in SKOV-3 decreased migration and invasion of cancer cells significantly confirmed

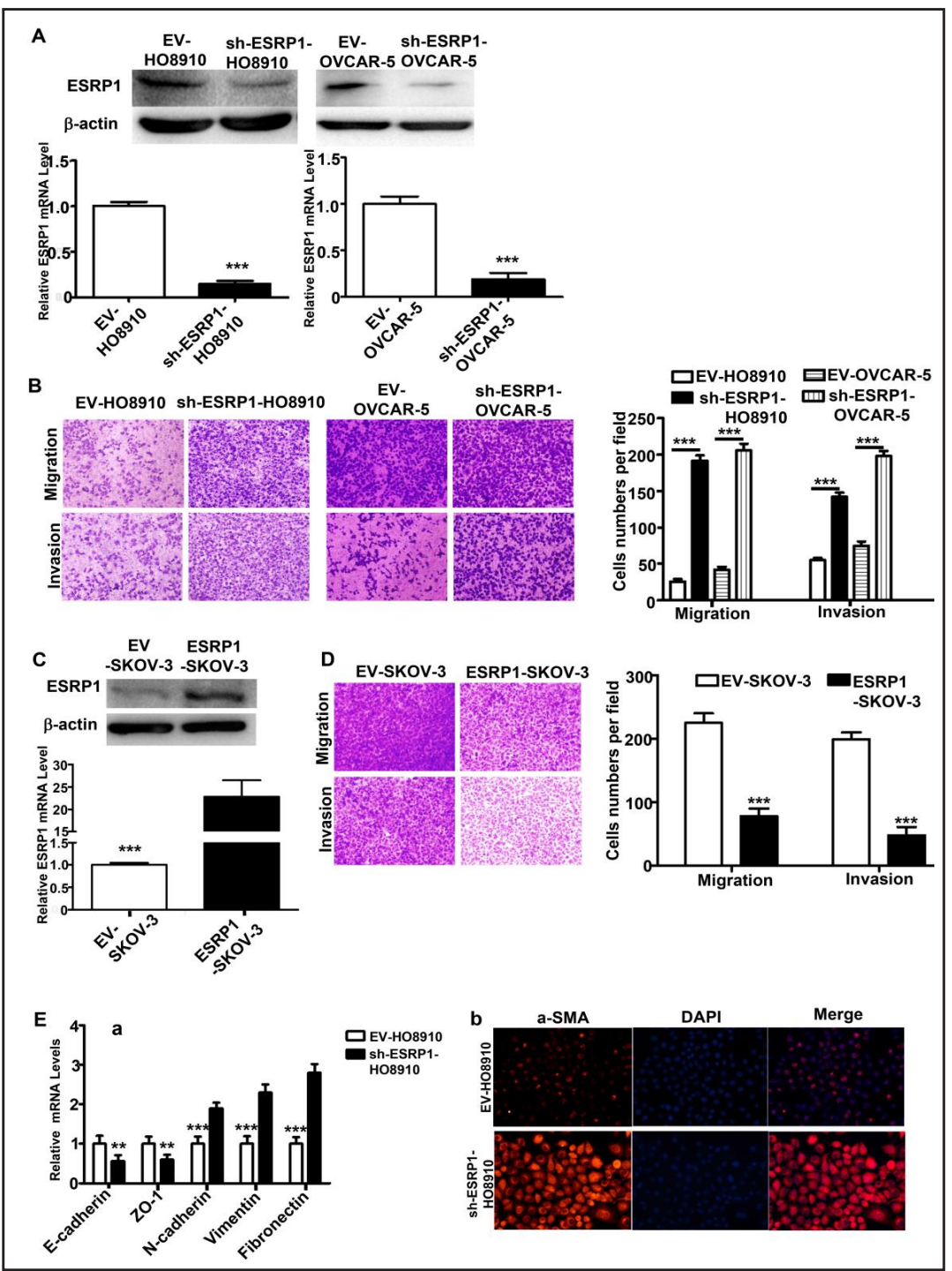
by a Corning Transwell

System. Error bars indicate SEM $\left({ }^{* * *} \mathrm{p}<0.001\right)$. E: (a) Compared with EV-H08910 cells, the expressions of mesenchymal markers N-cadherin,Vimentin and fibronectin were up-regulated whereas epithelial markers E-cadherin,ZO-1 were down-regulated in sh-ESRP1-H08910 cells, which were measured by qRT-PCR. Error bars indicate $\operatorname{SEM}\left({ }^{* *} \mathrm{p}<0.01,{ }^{* * *} \mathrm{p}<0.001\right)$; (b)Immunofluorescence cell staining(x200). Significant upregulation of mesenchymal marker $\alpha$-SMA in sh-ESRP1-H08910 cells compared with EV-HO8910 cells. Red staining indicates $\alpha$-SMA. DAPI staining (blue) indicates nuclei.

C) did decrease the ability of migration and invasion (Fig. 3D). Again, no difference in cell proliferation was observed (data not shown). ESRP1 was reported to play important roles in EMT process. We then examined several EMT markers by qRT-PCR after down-regulation of ESRP1 in H08910. The expressions of mesenchymal markers N-cadherin, Vimentin and fibronectin were up-regulated, whereas epithelial markers E-cadherin and ZO-1 were down-regulated in sh-ESRP1-H08910 when compared with EV-H08910 cells (Fig. 2 Ea). Immunofluorescence staining also revealed a significant up-regulation of mesenchymal marker $\alpha$-SMA in sh-ESRP1-H08910 cells (Fig. 2 Eb). All of the results indicate that EMT was induced by down-regulation of ESRP1, thus promoting invasion and migration of EOC cells. 


\section{Cellular Physiology Cell Physiol Biochem 2017;43:2489-2504

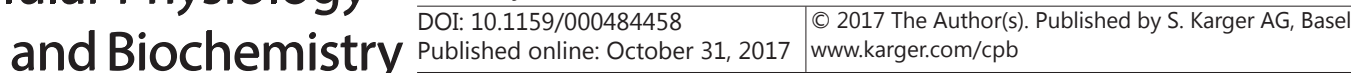 \\ Chen et al.: ESRP1 Plays an Important Role in EOC through EMT Process}

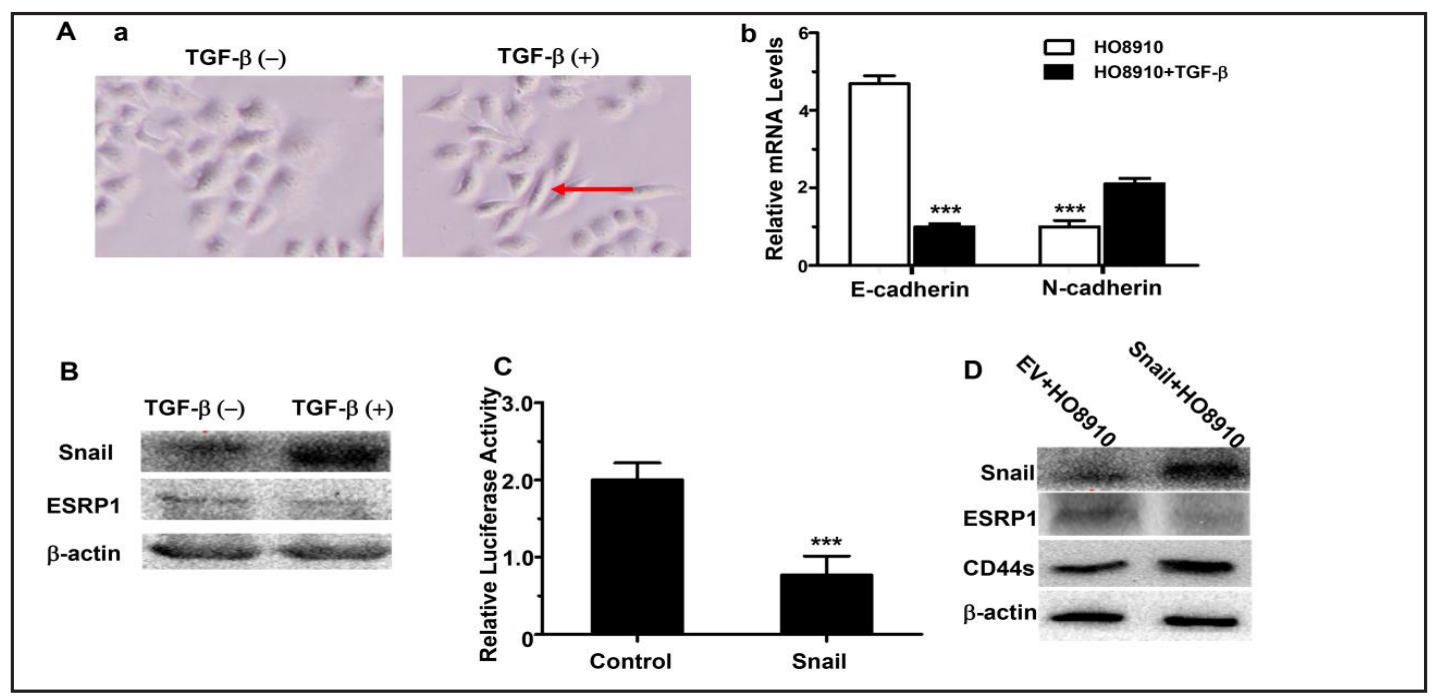

Fig. 3. ESRP1 was mediated in TGF- $\beta$-induced EMT and regulated by Snail in human EOC cellsA: H08910 cells were treated with TGF- $\beta(10 \mathrm{ng} / \mathrm{mL})$ for $48 \mathrm{~h}$. The cells were analyzed by phase-contrast microscopy. A physical change from a cobblestone-like epithelial morphology to an elongated fibroblastic appearance was observed and marked by the black arrow (a, x100). Levels of E-cadherin and N-cadherin before and after TGF- $\beta$-treatment were analyzed by qRT-PCR (b). Error bars indicate SEM $\left({ }^{* * *} \mathrm{p}<0.001\right)$. B: After TGF$\beta$-treatment, Snail and CD44s were continuous up-regulated while ESRP1 was decreased in Western Blot. $\beta$-actin served as a loading control. C: Relative luciferase activities in H08910 cells co-transfected with ESRP1 promoter luciferase reporter construct with Snail-expressing vector (Snail) or with compared empty vector (control). Photinus luciferase activities were normalized against Renilla in each group and compared. Error bars indicate SEM $\left({ }^{* * *} \mathrm{p}<0.001\right)$.D: A concomitant decreased expression of ESRP1 and an increase of CD44s were detected in Western Blot after Snail expression were increased by Snail-expression-vector in H08910 cells. $\beta$-actin served as a loading control.

ESRP1 mediated TGF- $\beta$-induced EMT was regulated by Snail in human EOC cells

Since TGF- $\beta$ is reported to be an important EMT mediator, we used TGF- $\beta$ to treat H08910. The cells did undergo EMT as reported. A physical change from a cobblestone-like epithelial morphology to an elongated fibroblastic appearance (Fig. $3 \mathrm{Aa}$ ), and a cadherin switch from epithelial E-cadherin to mesenchymal N-cadherin(Fig. $3 \mathrm{Ab}$ ) were observed. During TGF- $\beta$-induced EMT, Snail remained active and the expression of ESRP1 was decreased (Fig. 3 B). The mechanism by which ESRP1 is regulated during EMT has not been understood in EOC. A previous study showed that Snail can repress ESRP1 transcription via the zinc finger structure in $\mathrm{C}$ terminal of Snail binding to E-boxes in the ESRP1 promoter [25], thus allowing CD44 isoform switching during EMT. Therefore, we generated an ESRP1 luciferase reporter construct, which contains four ESRP1 E-boxes (CANNTG) upstream of the luciferase gene [25]. We found that co-transfection of Snail with the luciferase reporter construct into H08910 cells resulted in a 2.6-fold repression of ESRP1 luciferase activity (Fig. $3 \mathrm{C}$ ). This indicates that the E-box-containing region represents a functional segment of the ESRP1 promoter. Furthermore, we found that as the Snail-expression-vector in HO8910 cells (H08910-Snail) increased Snail expression, it led to a concomitant decreased expression of ESRP1 and an increase of CD44s on Western Blot (Fig. 3 D). These results suggest that Snail specifically represses ESRP1 transcription by directly binding to E-boxes in ESRP1 promoter and altering the ESRP1-associated CD44 splicing signature in EOC cells.

Down-regulation of ESRP1 promoted the invasion and migration of human EOC cells through isoform switching from CD44v to CD44s

This experiment highlighted the importance of ESRP1 in maintaining an epithelial phenotype and prompted us to investigate how ESRP1 modulates the alternative splicing, 


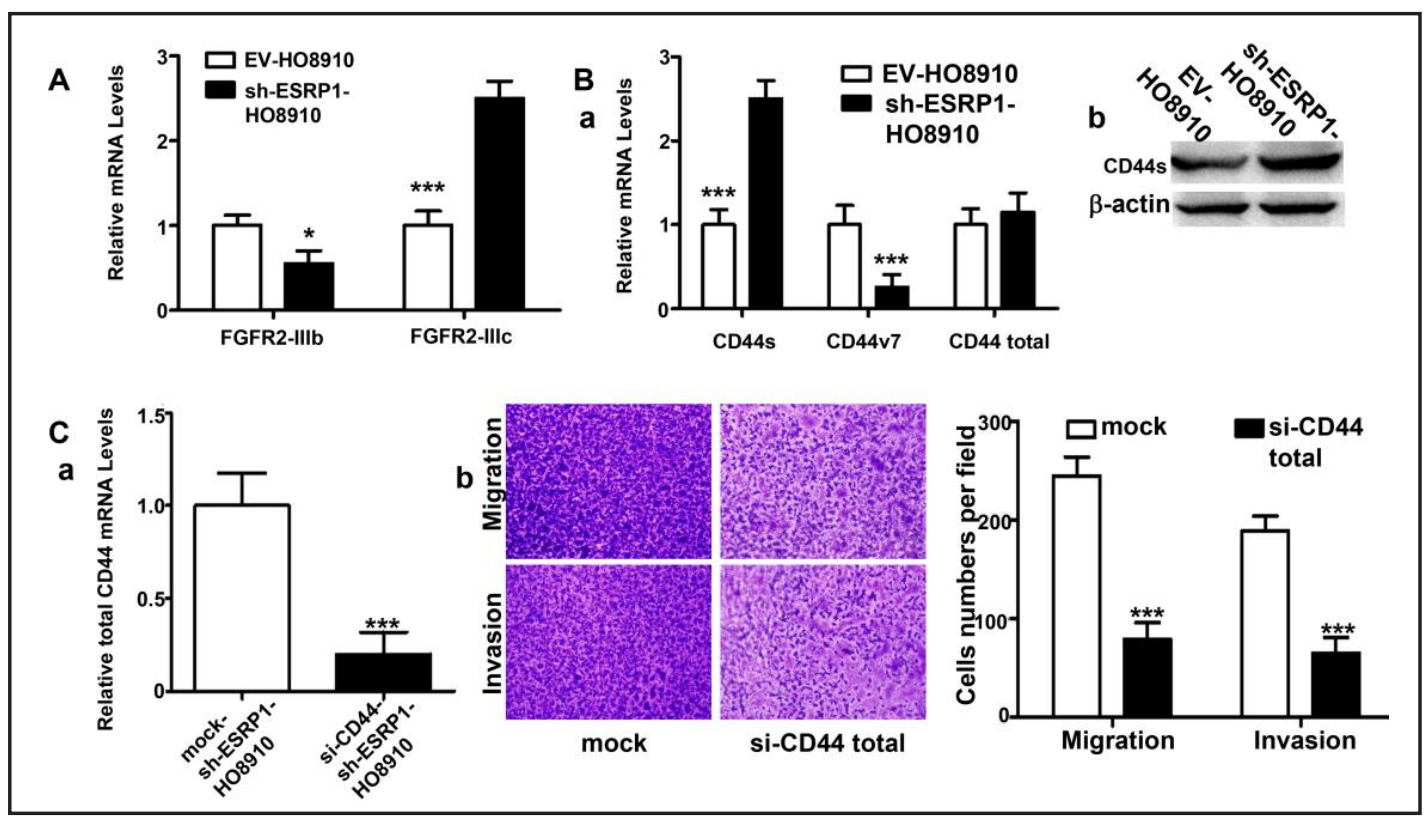

Fig. 4. Knock-down of ESRP1 promoted the invasion and migration of EOC through isoform switching of CD44.A: In qRT-PCR, stable knocking down of ESRP1 resulted in switching from FGFR2-IIIb to FGFR2-IIIc in H08910 cells. Error bars indicate SEM(***p<0.001). B: Stable knocking down of ESRP1 in H08910 cells resulted in switching from CD44v, mainly CD44v7, to CD44s while no change in total amount of CD44, confirmed by qRT-PCR(a) and/or Western Blot(b). Error bars indicate SEM $\left({ }^{* * *} \mathrm{p}<0.001\right)$. $\beta$-actin served as a loading control. C: (a) Sh-ESRP1-H08910 cells were transient transfected with siRNA targeting CD44 (siCD44-sh-H08910) and confirmed by qRT-PCR. (b) Migration and invasion of cancer cells were monitored by a Corning Transwell System. Error bars indicate SEM $(* * * p<0.001)$.

with focus on CD44 as the critical ESRP1 target gene. We used Sh-ESRP1H08910 cells to explore the alternative splicing events in EOC. We identified isoforms of FGFR2 and CD44 switching in ESRP1 down-regulated EOC cells through qRT-PCR. Downregulation of ESRP1 resulted in isoform switching from FGFR2-IIIb to FGFR2-IIIc (Fig. 4 A), as well as from CD44v (mainly CD44v7) to CD44s. However, the total amounts of CD44 in H08910 and Sh-ESRP1H08910 cells were the same (Fig. 4 B a-b). In addition, FGFR2-IIIc did not play a role in cell motility (data not shown). CD44 has been implicated in a variety of physiological processes in addition to cancer cell invasion and metastasis [29-34]. To assess the effect of the isoform switching from CD44v to CD44s in Sh-ESRP1-H08910, we decreased CD44 expression in shESRP1-H08910 cells by transfecting siRNA against CD44 (si-CD44-sh -ESRP1-H08910) (Fig. $4 \mathrm{Ca}$ ). Interestingly, the migratory and invasive capabilities of si-CD44-Sh-ESRP1H08910 were significantly decreased to the level where H08910 cells in the Transwell migration and invasion assay were, when comparing with Sh-ESRP1-H08910 cells (Fig. $4 \mathrm{Cb}$ ). Thus, the results demonstrated that ESRP1 suppressed EOC cell motility mainly by repressing CD44 isoform switching from CD44v to CD44s.

\section{Effects of ESRP1 in EOC intraperitoneal transplantation and metastasis in vivo}

To confirm the effects of ESRP1 in EOC cells in metastasis, we intraperitoneally injected the EV-H08910 or sh-ESRP1-H08910 cells to the nude mice. Four weeks after tumor cell intraperitoneal transplantation, mice were euthanized. Tumor growth and metastasis on each mouse were evaluated by tissue examination, tumor weight, and histopathology. We found that the mice injected with Sh-ESRP1-H08910 developed larger tumors and greater extent of abdominal metastasis than those injected with EV-H08910 (Fig. 5 A-B.). We also found that the sh-ESRP1-H08910/mice test group showed a higher expression of ESRP1 and a lower level of Snail than the EV-H08910 group /mice (Fig. 5C-D). Expression of CD44s 
Fig. 5. Effects of ESRP1 in EOC intraperitoneal transplantation and metastasis in vivoA and B: Sh-ESRP1-H08910/ mices showed greater peritoneal metastasis and developed larger tumor weights than EV-H08910 /mices. The metastatic lesions in each mices were marked by yellow circles in A. Error bars indicate SEM $\left({ }^{* *} \mathrm{p}<0.01\right)$ .C: Sh-ESRP1-H08910/ mice showed a higher expression of ESRP1 and a lower expression of Snail than the EVH08910 /mice in Western Blot. $\beta$-actin served as a loading control. D: In qRT-PCR, both Snail and CD44s expressions were decreased while ESRP1 expression was increased in the tumors from shESRP1-H08910/mice, compared with EV-

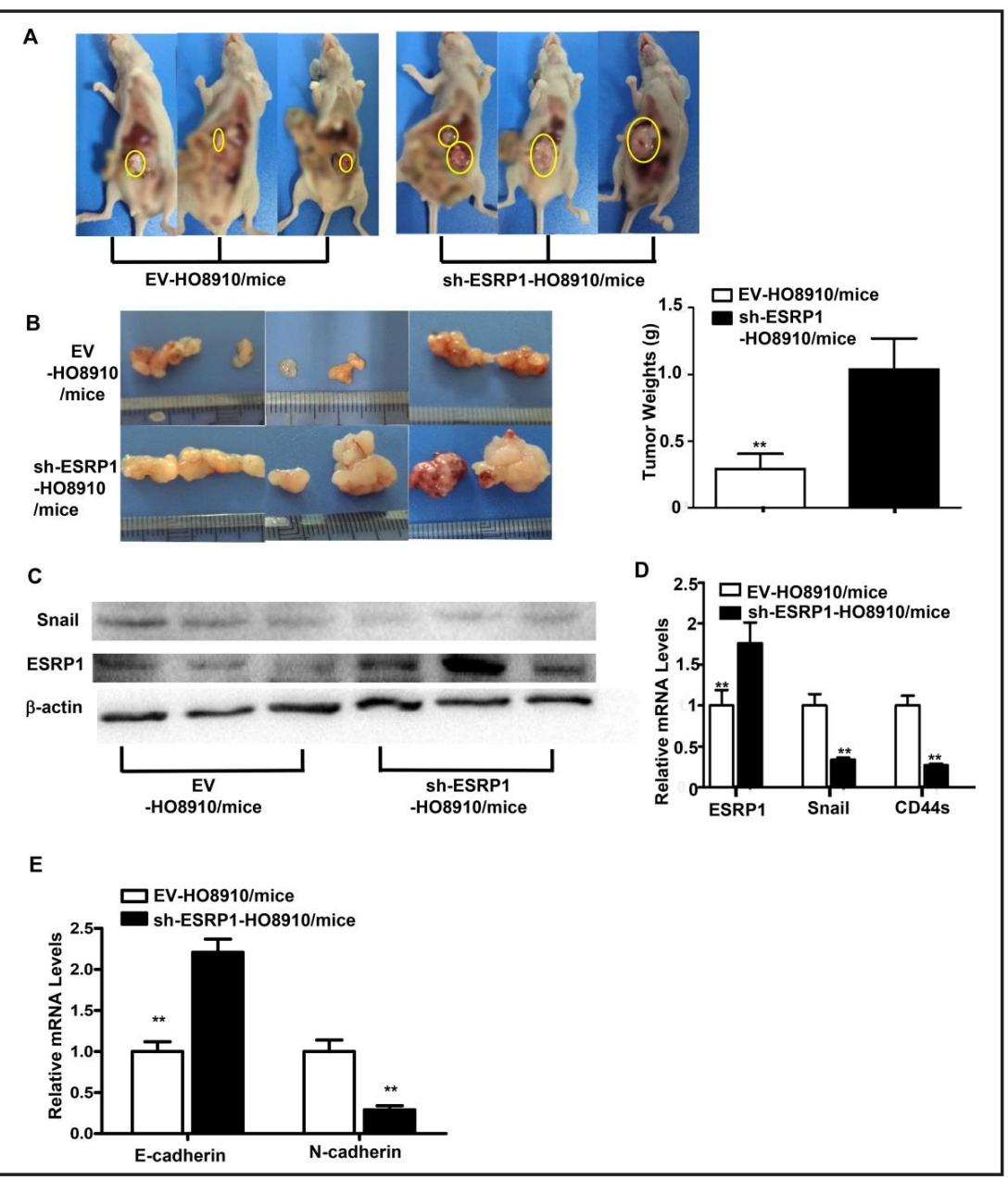
H08910/mice. Error

bars indicate $\operatorname{SEM}\left({ }^{* *} \mathrm{p}<0.01\right)$; E: E-cadherin expression was increased while $\mathrm{N}$-caherin was decreased in sh-ESRP1-H08910/mice, confirmed by qRT-PCR. Error bars indicate SEM(**p<0.01).

was decreased in the tumors from the sh-ESRP1-H08910 mice, in comparison to the tumors from the EV-H08910 mice (Fig. 5 D). Meanwhile, E-cadherin expression was increased in the former group while N-cadherin was decresed (Fig. $5 \mathrm{E}$ ). Thus, we were able to confirm that ESRP1 induced EMT promoted EOC cells to migrate from their primary tumor sites in the in vivo models; further, a MET process was detected in metastatic sites, suggesting MET is needed for tumor engraftment and growth of EOC cells at metastatic sites.

\section{Discussion}

It has been reported that ESRP1 is critical in regulating cancer subtype specific alternative splicing programs and in mediating EMT specific splicing programs $[35,36]$. This study characterized the mechanisms and effects of ESRP1 on metastatic behavior in EOC. High expression of ESRP1 was detected in EOC patients and associated with advanced FIGO stage and poor prognosis through statistical analysis in this study. ESRP2, which is the other important member in the RBM family of RNA-binding proteins, has reportedly played multiple roles in tumor progression [18]. But, in our study, no statistically significant difference in ESRP2 expression was observed between normal ovarian and EOC tissues in

\section{KARGER}


Affymetrix HTA 2.0 microarray and IHC test (data not shown). When we generated both down-regulated and up-regulated ESRP1 cell lines, decreasing expression of ESRP1 in H08910 and OVCAR5 promoted metastatic behavior of EOC cells including migration and invasion both in vivo and in vitro. Over-expression of ESRP1 decreased migration and invasion in EOC cells. In addition, EMT induced by down-regulation of ESRP1 expression promoted a program of alternative splicing associated with metastasis.

We found that products in alternative splicing pathways can be used to identify various breast cancer subtypes, but none were previously identified in EOC. Here, we discovered that a major alternative spliced gene CD44 in ESRP1-expressing EOC cells was associated with cell migration and invasion in EOC. We found that CD44 isoform switching is involved in EMT and metastasis. CD44 expression was reduced in ESRP1 down-regulated EOC cells. Its levels directly correlate with the reduced level of migration and invasion observed in the ESRP1 down-regulated EOC cells. Thus, ESRP1-regulated alternative splicing of CD44 mRNA enhances EOC cells migration and invasion.

It is important to elucidate the mechanisms underlying ESRP1 expression. Previous reports showed that EMT-associated transcription factors $(\delta E F 1, S I P 1$, Snail, Slug, and Twist) down-regulate ESRP1 or ESRP2. ESRP1 expression could be affected by the epigenetic status of the ESRP1 locus, as well as by the EMT status. In some cases, splicing genes were themselves differentially spliced. For example, a long transcript variant of Rbfox2 (NM_053104) was up-regulated in Wnt-5a-4T1 cells while the short variant (NM_001110830) was down-regulated [37]. In the case of EOC, ESRP1 expression plays a role in EMT-related mechanisms since there were differences in the expression of EMT markers in ESRP1 down-regulated EMT cells. TGF- $\beta$ induced EMT in EOC cells by triggering the down-regulation of ESRP1. Similar to the previous study in human mammary epithelial cells and HCT116 colon carcinoma cells [25], Snail also regulated ESRP1 expression by binding directly to the E-box structure in the promoter of ESRP1, as confirmed by a Dual-Luciferase Reporter assay system. Up-regulation of Snail caused a repression of ESRP1 in EOC cells. High ESRP1 can inhibit Snail-induced EMT in EOC cells.

In this study, we showed that the phenotypic and tumorigenic properties of EOC cells are relative to the type of CD44 isoform. A CD44s isoform displays an EMT phenotype, and is more invasive in EOC cells. In comparison, CD44v isoform cells were more epitheliallike and less invasive. A study by Brown et al. showed that an EMT phenotype (mainly the CD44s isoform) and EMT induction in HMLE cells was associated with a switch from mainly CD44v isoform expression to CD44s predominance [34]. Numbers of studies suggest that expression of CD44 variants including CD44v3 and v6 are associated with metastatic lesions [21,38-41]. The functional differences of CD44 molecules that possess single or multiple variant exons is not clear and needs further investigation in EOC. The high level of CD44s expression in EOC suggests that CD44s isoform plays an important role in tumor cell plasticity contributing to increased invasiveness. However, this study does not rule out the possibility that minor variant isoforms contribute significantly to these properties.

The functional significance of ESRP1 in H08910 cells was further assessed by using an orthotopic mice model. Tumors developed from ESRP1 down-regulated cells grew and metastasized more rapidly than untreated EOC cells. However, once tumors grew as orthotopic implants in vivo, the tumor cells underwent CD44 isoform switching, re-gained ESRP1 expression, and gained the epithelial marker E-cadherin, which is expressed at a low or undetectable level in the original ESRP1 down-regulated EOC cells. This phenomenon suggests that tumor cells from ESRP1 down-regulated EOC in mice undergo MET and that a CD44 isoform switch may be required for this to occur.

EMT and MET are dynamic processes in tumor progression. The former, EMT, is involved in invasion, tumor metastasis and stem cell properties; whereas converting back to the epithelial phenotype may favor tumor growth [42]. Once engrafted, EMT-like tumor cells may convert to MET. In this study, EMT appears to be closely associated with the loss of ESRP1 and an increase in expression of CD44s. Our observation is consistent with

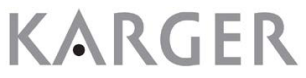




\section{Cellular Physiology Cell Physiol Biochem 2017;43:2489-2504 and Biochemistry \begin{tabular}{l|l} 
DOI: 10.1159/000484458 \\
Published 201,2017 The Author(s). Published by S. Karger AG, Basel
\end{tabular} \\ Chen et al.: ESRP1 Plays an Important Role in EOC through EMT Process}

the premise that the molecular basis of CD44 isoform switching is regulated by ESRP1 in EOC. Therefore, ESRP1 likely controls CD44 isoform switching and plays a critical role in promoting the epithelial state. Down-regulation of ESRP1 likely facilitates expression of mainly the CD44s form. EOC cells expressing a CD44s isoform predominantly display an EMT phenotype in vitro. The cells are highly invasive and form tumors and metastases more rapidly in vivo. Once engrafted in vivo, EMT-like tumor cells (sh-ESRP1-H08910) may convert to MET more rapidly with the high-expression of ESRP1. Because of the lack of effective methods for early diagnosis, many EOC patients are in advanced stages and already have orthotopic implants when they go to clinic. This may explain why expression of ESRP1 was higher in EOC tumors than in normal ovarian tissues and that high ESRP1 expression in EOC was associated with poor clinical outcomes as we presented. Interestingly, the expression of ESRP1 is also plastic in oral squamous cell carcinogenesis [18]: ESRP1 is up-regulated relative to its level in normal epithelium but down-regulated in invasive fronts. Importantly, ESRP1 is re-expressed in the lymph nodes, where carcinoma cells metastasize and colonize.

In conclusion, our study has shown that alternative splicing of CD44 by ESRP1 induces EMT directly and affects EOC progression; ESRP1 is a critical factor in maintaining an epithelial phenotype and serves as a barrier for the transition to the mesenchymal state. Since EMT is considered an early step in metastatic progression and EMT is frequently reactivated during cancer metastasis and recurrence, defining the role of splicing factors such as ESRP1 in regulating EMT may advance our ability to prevent these deadly aspects of EOC progression. Novel biomarkers of EMT that we identified in the Snail-ESRP1-CD44 axis may guide the development of new diagnostic and prognostic tools if confirmed in a large cohort of patients.

\section{Abbreviations}

EOC (Epithelial ovarian cancer); MET (Mesenchymal-epithelial transition); EMT (Epithelial-mesenchymal transition); ESRP1 (Epithelial splicing regulatory protein 1); ESRP2 (Epithelial splicing regulatory protein 2); TMA (Tissue microarray); IHC (Immunohistochemistry); IF (Immunofluorescence); qRT-PCR (Quantitative real-time PCR); CCK-8 (Cell Counting Kit-8); OS (overall-survival); PFS (progression-free-survival).

\section{Acknowledgements}

We thank all of our patients for participation in this study. This work was supported by a Grant from National Natural Science Foundation of China (No.81101996), a Grant from the Planned Science and Technology Project of Hunan Province, China (No. 2014FJ2015), and a Grant from Chinese Anti-Cancer Association (No.29).

\section{Disclosure Statement}

The authors declare that they have no competing interests.

\section{References}

1 Siegel RL, Miller KD, Jemal A: Cancer statistics, 2016. CA Cancer J Clin 2016;66:7-30.

-2 Deng Y, Wang Z, Zhang F, Qiao M, Yan Z, Wei Q, Wang J, Liu H, Fan J, Zou Y, Liao J, Hu X, Chen L, Yu X, Haydon RC, Luu HH, Qi H, He TC, Zhang J: A blockade of igf signaling sensitizes human ovarian cancer cells to the anthelmintic niclosamide-induced anti-proliferative and anticancer activities. Cell Physiol Biochem 2016;39:871-888. 


\section{Cellular Physiology Cell Physiol Biochem 2017;43:2489-2504 \begin{tabular}{ll|l} 
DOI: 10.1159/000484458 & O 2017 The Author(s). Published by S. Karger AG, Basel \\
www.karger.com/cpb
\end{tabular}}

- Y Ying X, Wei K, Lin Z, Cui Y, Ding J, Chen Y, Xu B: Microrna-125b suppresses ovarian cancer progression via suppression of the epithelial-mesenchymal transition pathway by targeting the set protein. Cell Physiol Biochem 2016;39:501-510.

4 Song N, Liu H, Ma X, Zhang S: Placental growth factor promotes metastases of ovarian cancer through mir543-regulated mmp7. Cell Physiol Biochem 2015;37:1104-1112.

5 Li C, Ding H, Tian J, Wu L, Wang Y, Xing Y, Chen M: Forkhead box protein c2 promotes epithelialmesenchymal transition, migration and invasion in cisplatin-resistant human ovarian cancer cell line (skov3/cddp). Cell Physiol Biochem 2016;39:1098-1110. Thiery JP: Epithelial-mesenchymal transitions in tumour progression. Nat Rev Cancer 2002;2:442-454. Baum B, Settleman J, Quinlan MP: Transitions between epithelial and mesenchymal states in development and disease. Semin Cell Dev Biol 2008;19:294-308.

-8 Korpal M, Ell BJ, Buffa FM, Ibrahim T, Blanco MA, Celi TT, Mercatali L, Khan Z, Goodarzi H, Hua Y, Wei Y, Hu G, Garcia BA, Ragoussis J, Amadori D, Harris AL, Kang Y: Direct targeting of sec23a by mir-200s influences cancer cell secretome and promotes metastatic colonization. Nature Med 2011;17:1101-1108.

-9 Tsai JH, Donaher JL, Murphy DA, Chau S, Yang J: Spatiotemporal regulation of epithelial-mesenchymal transition is essential for squamous cell carcinoma metastasis. Cancer Cell 2012;22:725-736.

10 Wang ET, Sandberg R, Luo S, Khrebtukova I, Zhang L, Mayr C, Kingsmore SF, Schroth GP, Burge CB: Alternative isoform regulation in human tissue transcriptomes. Nature 2008;456:470-476.

11 Black DL: Mechanisms of alternative pre-messenger rna splicing. Annu Rev Biochem 2003;72:291-336.

12 Venables JP: Aberrant and alternative splicing in cancer. Cancer Res 2004;64:7647-7654.

-13 Deloria AJ, Hoflmayer D, Kienzl P, Lopatecka J, Sampl S, Klimpfinger M, Braunschmid T, Bastian F, Lu L, Marian B, Stattner S, Holzmann K: Epithelial splicing regulatory protein 1 and 2 paralogues correlate with splice signatures and favorable outcome in human colorectal cancer. Oncotarget 2016;7:73800-73816.

14 Warzecha CC, Shen S, Xing Y, Carstens RP: The epithelial splicing factors esrp1 and esrp2 positively and negatively regulate diverse types of alternative splicing events. RNA Biol 2009;6:546-562.

15 Horiguchi K, Sakamoto K, Koinuma D, Semba K, Inoue A, Inoue S, Fujii H, Yamaguchi A, Miyazawa K, Miyazono K, Saitoh M: TGF-b drives epithelial-mesenchymal transition through deltaef1-mediated downregulation of esrp. Oncogene 2012;31:3190-3201.

16 Leontieva OV, Ionov Y: Rna-binding motif protein 35a is a novel tumor suppressor for colorectal cancer. Cell Cycle 2009;8:490-497.

17 Ueda J, Matsuda Y, Yamahatsu K, Uchida E, Naito Z, Korc M, Ishiwata T: Epithelial splicing regulatory protein 1 is a favorable prognostic factor in pancreatic cancer that attenuates pancreatic metastases. Oncogene 2014;33:4485-4495.

18 Ishii H, Saitoh M, Sakamoto K, Kondo T, Katoh R, Tanaka S, Motizuki M, Masuyama K, Miyazawa K: Epithelial splicing regulatory proteins 1 (esrp1) and 2 (esrp2) suppress cancer cell motility via different mechanisms. J Biol Chem 2014;289:27386-27399.

19 Warzecha CC, Sato TK, Nabet B, Hogenesch JB, Carstens RP: Esrp1 and esrp2 are epithelial cell-type-specific regulators of fgfr2 splicing. Mol Cell 2009;33:591-601.

20 Ishiwata T, Matsuda Y, Yamamoto T, Uchida E, Korc M, Naito Z: Enhanced expression of fibroblast growth factor receptor 2 iiic promotes human pancreatic cancer cell proliferation. Am J Pathol 2012;180:19281941.

-21 Zhao S, Chen C, Chang K, Karnad A, Jagirdar J, Kumar AP, Freeman JW: Cd44 expression level and isoform contributes to pancreatic cancer cell plasticity, invasiveness, and response to therapy. Clin Cancer Res 2016;22:5592.

22 National comprehensive cancer network. (nccn) clinical practice guidelines in oncology. Ovarian cancer (including fallopian tube cancer and primary peritoneal cancer), version1. 2016. Https://www.Nccn.Org/ professionals/physician_gls/f_guidelines.Asp\#ovarian.

23 Zeppernick F, Meinhold-Heerlein I: The new figo staging system for ovarian, fallopian tube, and primary peritoneal cancer. Arch Gynecol Obstet 2014;290:839-842.

24 Chen L, Yao Y, Sun L, Zhou J, Liu J, Wang J, Li J, Tang J: Clinical implication of the serum galectin-1 expression in epithelial ovarian cancer patients. J Ovarian Res 2015;8:78.

25 Reinke LM, Xu Y, Cheng C: Snail represses the splicing regulator epithelial splicing regulatory protein 1 to promote epithelial-mesenchymal transition. J Biol Chem 2012;287:36435-36442. 


\section{Cellular Physiology Cell Physiol Biochem 2017;43:2489-2504 \begin{tabular}{l|l|l} 
DOI: 10.1159/000484458 & Ond Biochemistry Published online: October 31, 2017 & $\begin{array}{l}\text { 2 2017 The Author(s). Published by S. Karger AG, Basel } \\
\text { www.karger.com/cpb }\end{array}$
\end{tabular} \\ Chen et al.: ESRP1 Plays an Important Role in EOC through EMT Process}

-26 Shahab SW, Matyunina LV, Mezencev R, Walker LD, Bowen NJ, Benigno BB, McDonald JF: Evidence for the complexity of microrna-mediated regulation in ovarian cancer: A systems approach. PLoS One 2011;6:e22508.

-27 Bowen NJ, Walker LD, Matyunina LV, Logani S, Totten KA, Benigno BB, McDonald JF: Gene expression profiling supports the hypothesis that human ovarian surface epithelia are multipotent and capable of serving as ovarian cancer initiating cells. BMC Med Genomics 2009;2:71.

28 Mok SC, Bonome T, Vathipadiekal V, Bell A, Johnson ME, Wong KK, Park DC, Hao K, Yip DK, Donninger H, Ozbun L, Samimi G, Brady J, Randonovich M, Pise-Masison CA, Barrett JC, Wong WH, Welch WR, Berkowitz RS, Birrer MJ: A gene signature predictive for outcome in advanced ovarian cancer identifies a survival factor: Microfibril-associated glycoprotein 2. Cancer Cell 2009;16:521-532.

29 Orian-Rousseau V: Cd44, a therapeutic target for metastasising tumours. Eur J Cancer 2010;46:1271-1277.

-30 Suzuki H, Yamashiro K: Reduced expression of cd44 v3 and v6 is related to invasion in lung adenocarcinoma. Lung Cancer 2002;38:137-141.

-31 Zhao LH, Lin QL, Wei J, Huai YL, Wang KJ, Yan HY: Cd44v6 expression in patients with stage ii or stage iii sporadic colorectal cancer is superior to cd44 expression for predicting progression. Int J Clin Exp Pathol 2015;8:692-701.

32 Wielenga VJ, Heider KH, Offerhaus GJ, Adolf GR, Van BF, Ponta H, Herrlich P, Pals ST: Expression of cd44 variant proteins in human colorectal cancer is related to tumor progression. Cancer Res 1993;53:47544756.

33 Yae T, Tsuchihashi K, Ishimoto T, Motohara T, Yoshikawa M, Yoshida GJ, Wada T, Masuko T, Mogushi K, Tanaka H, Osawa T, Kanki Y, Minami T, Aburatani H, Ohmura M, Kubo A, Suematsu M, Takahashi K, Saya H, Nagano 0: Alternative splicing of cd44 mrna by esrp1 enhances lung colonization of metastatic cancer cell. Nat Commun 2012;3:883.

34 Brown RL, Reinke LM, Damerow MS, Perez D, Chodosh LA, Yang J, Cheng C: Cd44 splice isoform switching in human and mouse epithelium is essential for epithelial-mesenchymal transition and breast cancer progression. J Clin Invest 2011;121:1064-1074.

-35 Fici P, Gallerani G, Morel AP, Mercatali L, Ibrahim T, Scarpi E, Amadori D, Puisieux A, Rigaud M, Fabbri F: Splicing factor ratio as an index of epithelial-mesenchymal transition and tumor aggressiveness in breast cancer. Oncotarget 2016;8:2423-2436.

-36 Yao J, Caballero OL, Huang Y, Lin C, Rimoldi D, Behren A, Cebon JS, Hung MC, Weinstein JN, Strausberg RL, Zhao Q: Altered expression and splicing of esrp1 in malignant melanoma correlates with epithelialmesenchymal status and tumor-associated immune cytolytic activity. Cancer Immunol Res 2016;4:552-561.

37 Wang J, Liao QJ, Zhang Y, Zhou H, Luo CH, Tang J, Wang Y, Tang Y, Zhao M, Zhao XH, Zhang QY, Xiao L: Trpm7 is required for ovarian cancer cell growth, migration and invasion. Biochem Biophys Res Commun 2014;454:547-553.

-38 Wang SJ, Wreesmann VB, Bourguignon LY: Association of cd44 v3-containing isoforms with tumor cell growth, migration, matrix metalloproteinase expression, and lymph node metastasis in head and neck cancer. Head Neck 2007;29:550-558.

39 Kuncova J, Kostrouch Z, Viale M, Revoltella R, Mandys V: Expression of cd44v6 correlates with cell proliferation and cellular atypia in urothelial carcinoma cell lines 5637 and ht1197. Folia Biol (Praha) 2005;51:3-11.

40 Kuniyasu H, Chihara Y, Kubozoe T, Takahashi T: Co-expression of cd44v3 and heparanase is correlated with metastasis of human colon cancer. Int J Mol Med 2002;10:333-337.

41 Rall CJ, Rustgi AK: Cd44 isoform expression in primary and metastatic pancreatic adenocarcinoma. Cancer Res 1995;55:1831-1835.

42 Brabletz T: Emt and met in metastasis: Where are the cancer stem cells? Cancer Cell 2012;22:699-701. 